\title{
TO THE NUMERICAL MODELING OF SELF-SIMILAR SOLUTIONS OF REACTION-DIFFUSION SYSTEM OF THE ONE TASK OF BIOLOGICAL POPULATION OF KOLMOGOROV-FISHER TYPE
}

\author{
M.M. Aripov ${ }^{1}$, D.K. Muhamediyeva ${ }^{2}$ \\ ${ }^{I}$ Doctor of physical and mathematical Sciences, PhD of the National University of Uzbekistan \\ ${ }^{2}$ Master of the National University of Uzbekistan \\ mirsaidaripov@mail.ru,matematichka@inbox.ru
}

\begin{abstract}
On the basis of self-similar analysis of solutions investigated properties of solutions of a nonlinear system of reaction-diffusion of one biological task of Kolmogorov-Fisher type. Offered suitable initial approximations for quickly convergence iteration process. Numerical experiments are carried out with visualization for different values of parameters of the system.
\end{abstract}

Keywords: biological population, nonlinear system of differential equations, initial approximation, numerical, iteration process, self-similar solution.

\section{INTRODUCTION.}

Currently, research of linear mathematical models of physical, biological, chemical and other processes are comfortable, because for the underlying linear partial differential equations developed their general solving methods. But in applied tasks real physical processes are nonlinear, and to adequately describe them should be used nonlinear mathematical models.

It is interesting from the point of view of applications, study such classes of nonlinear differential equations in which the unknown function and the derivative of this function includes by exponential way [1-4].

These types of nonlinearities are often found in the tasks of biological population, chemistry, medicine, and other [1-4]. Population is defined as a group of organisms of the same species (within which individuals can exchange genetic information) that occupies a specific space and functioning as part of the biological community.

Consider the model of two competing populations with nonlinear diffusion. The problem of mathematical description of biological competition has a long history. The most famous attempt to describe the competition of several populations is the Volterra-Lotka's system [5]. The main statement relating to competing communities is the principle of Gause [6]. It states that the result of the competitive interaction between the two species occupying one ecological niche will be the displacement of the least fit.
In the last decade due to the growing interest in the study of the problems of structure formation models of multicomponent biological systems competing in the class of systems of nonlinear equations of the reaction-diffusion given a new momentum [4,9]. Introduction assumptions about the spatial habitat of competing species allows for a different look at the processes and results of the competition.

Consider a spatial analogue of Volterra-Lotka competition system with nonlinear exponential dependence of the diffusion coefficient on the density of the population. In the case of the simplest volterra's competitive interactions between populations can be constructed numerically, and in some cases analytically, heterogeneous in space solutions [9].

\section{STATEMENT OF THE TASK}

Consider in $\mathrm{Q}=\left\{(\mathrm{t}, \mathrm{x}): 0<\mathrm{t}<\infty, \quad \mathrm{x} \in \mathrm{R}^{2}\right\}$ parabolic system of two quasilinear equations of reaction-diffusion of the task of biological population of Kolmogorov-Fisher type

$$
\left\{\begin{array}{c}
\frac{\partial u_{1}}{\partial t}=\frac{\partial}{\partial x}\left(D_{1} u_{1}^{\sigma_{1}} \frac{\partial u_{1}}{\partial x}\right)+k_{1}(t) u_{1} \cdot\left(1-u_{2}^{\beta_{1}}\right), \\
\frac{\partial u_{2}}{\partial t}=\frac{\partial}{\partial x}\left(D_{2} u_{2}^{\sigma_{2}} \frac{\partial u_{2}}{\partial x}\right)-k_{2}(t) u_{2} \cdot\left(1-u_{1}^{\beta_{2}}\right), \\
u_{1 \mid t=0}=u_{10}(x),
\end{array}\right.
$$




$$
\left.u_{2}\right|_{t=0}=u_{20}(x)
$$

that describes the process of biological populations in a nonlinear two-component environment, diffusion, which coefficient equal to $D_{1} u_{1}^{\sigma_{1}}$ and $D_{2} u_{2}^{\sigma_{2}}, \sigma_{1}, \sigma_{2}, \beta_{1}, \beta_{2}$ positive real numbers, $u_{1}=u_{1}(t, x) \geq 0, u_{2}=u_{2}(t, x) \geq 0$ - search solutions.

Cauchy problem and boundary tasks for the system (1) in the one dimensional and multidimensional cases investigated by many authors [ 4-9 ].

Purpose of this work is to study the qualitative properties of the solutions of the task (1), (2) on the basis of self-similar analysis and numerical solutions by using methods of modern computer technologies, research of methods of linearization to the convergence of iterative process with further visualization. Found estimates of solutions and emerging wherein free boundary, that gives the chance to choose the appropriate initial approximation [4] for each value of the numeric parameters.

Let's construct self-similar system of equations (1)-(2) simpler for research system of equations.

\section{CONSTRUCTION OF SELF-SIMILAR SYSTEM OF EQUATIONS}

We will construct self-similar system of equations by the method of nonlinear splitting [4].

Replacement in (1)

$$
\begin{aligned}
& u_{1}(t, x)=e^{k_{1} t} v_{1}(t, x), \\
& u_{2}(t, x)=e^{k_{2} t} v_{2}(t, x)
\end{aligned}
$$

lead (1) to the form:

$$
\left\{\begin{array}{l}
\frac{\partial v_{1}}{\partial \tau}=\frac{\partial}{\partial x}\left(D_{1} v_{1}^{\sigma_{1}} \frac{\partial v_{1}}{\partial x}\right)+k_{1} e^{\left(\left(\beta_{1} k_{2}+k_{1}\right)-\left(\sigma_{1}+1\right) k_{1}\right) t} v_{1} v_{2}^{\beta_{1}} \\
\frac{\partial v_{2}}{\partial \tau}=\frac{\partial}{\partial x}\left(D_{2} v_{2}^{\sigma_{2}} \frac{\partial v_{2}}{\partial x}\right)+k_{2} e^{\left(\left(\beta_{2} k_{1}+k_{2}\right)-\left(\sigma_{2}+1\right) k_{2}\right) t} v_{1}^{\beta_{2}} v_{2}
\end{array}\right.
$$

$$
\begin{aligned}
& \left.v_{1}\right|_{t=0}=v_{10}(x), \\
& \left.v_{2}\right|_{t=0}=v_{20}(x),
\end{aligned}
$$

By choosing $\sigma_{1} k_{1}=\sigma_{2} k_{2}$, we obtain the following system of equations,

$$
\left\{\begin{array}{l}
\frac{\partial v_{1}}{\partial \tau}=\frac{\partial}{\partial x}\left(D_{1} v_{1}^{\sigma_{1}} \frac{\partial v_{1}}{\partial x}\right)-a_{1} \tau^{b_{1}} v_{1} v_{2}^{\beta_{1}} \\
\frac{\partial v_{2}}{\partial \tau}=\frac{\partial}{\partial x}\left(D_{2} v_{2}^{\sigma_{2}} \frac{\partial v_{2}}{\partial x}\right)-a_{2} \tau^{b_{2}} v_{1}^{\beta_{2}} v_{2}
\end{array}\right.
$$

Where,

$$
\begin{aligned}
& a_{1}=\left(\delta_{1} k_{1}\right)^{b_{1}}, a_{2}=\left(\delta_{2} k_{2}\right)^{b_{2}}, \\
& b_{1}=\left[\left(\beta_{1} k_{2}+k_{1}\right)-\left(\sigma_{1}+1\right) k_{1}\right] / \sigma_{1} k_{1}, \\
& b_{2}=\left[\left(\beta_{2} k_{1}+k_{2}\right)-\left(\sigma_{2}+1\right) k_{2}\right] / \sigma_{2} k_{2} .
\end{aligned}
$$

Below we describe one way of obtaining self-similar system for the equations system (4). It consists of the following. We first find the solution of ordinary differential equations system

in the form

$$
\left\{\begin{array}{l}
\frac{d \bar{v}_{1}}{d \tau}=-a_{1} \tau^{b_{1}} v_{1} v_{2}^{\beta_{1}} \\
\frac{d \bar{v}_{2}}{d \tau}=-a_{2} \tau^{b_{2}} v_{1}^{\beta_{2}} v_{2}
\end{array}\right.
$$

$$
\begin{gathered}
\bar{\nu}_{1}(t)=c_{1}(\tau+T)^{-\gamma_{1}}, \\
\bar{\nu}_{2}(t)=c_{2}(\tau+T)^{-\gamma_{2}}, T>0,
\end{gathered}
$$

Where

$$
\begin{aligned}
& c_{1}=\left[\frac{\gamma_{1}}{a_{1}}\left(\frac{\gamma_{2}}{a_{2}}\right)^{\beta_{1}}\right]^{-\frac{1}{\beta_{1} \beta_{2}-1}}, \\
& \gamma_{1}=\frac{\left(b_{1}+1\right)+\beta_{1}\left(b_{2}+1\right)}{\beta_{1} \beta_{2}-1}, \\
& c_{2}=\left[\left(\frac{\gamma_{1}}{a_{1}}\right)^{\beta_{2}} \frac{\gamma_{2}}{a_{2}}\right]^{-\frac{1}{\beta_{1} \beta_{2}-1}}, \\
& \gamma_{2}=\frac{\left(b_{2}+1\right)-\beta_{2}\left(b_{1}+1\right)}{\beta_{1} \beta_{2}-1} .
\end{aligned}
$$


And then solution of system (3)-(4) is sought in the form

$$
\begin{gathered}
v_{1}(t, x)=\bar{v}_{1}(t) w_{1}(\tau, x), \\
v_{2}(t, x)=\bar{v}_{2}(t) w_{2}(\tau, x),
\end{gathered}
$$

Where $\tau=\tau(t)$ chosen as

$$
\tau(t)=\int \bar{v}_{1}^{\sigma_{1}}(t) d t= \begin{cases}\frac{c_{1}^{\sigma_{1}}}{1-\gamma_{1} \sigma_{1}}(T+t)^{1-\gamma_{1} \sigma_{1}}, & \text { if } 1-\gamma_{1} \sigma_{1} \neq 0, \\ \ln (T+t), & \text { if } 1-\gamma_{1} \sigma_{1}=0 .\end{cases}
$$

Then for $w_{i}(\tau, x), i=1,2$ we obtain a system of equations

$$
\left\{\begin{array}{l}
\frac{\partial w_{1}}{\partial \tau}=\frac{\partial}{\partial x}\left(D_{1} w_{1}^{\sigma_{1}} \frac{\partial w_{1}}{\partial x}\right)-\psi_{1}\left(w_{1} w_{2}^{\beta_{1}}-w_{1}\right) \\
\frac{\partial w_{2}}{\partial \tau}=\frac{\partial}{\partial x}\left(D_{2} w_{2}^{\sigma_{2}} \frac{\partial w_{2}}{\partial x}\right)-\psi_{2}\left(w_{2} w_{1}^{\beta_{2}}-w_{2}\right)
\end{array},\right.
$$

Where

$$
\psi_{i}= \begin{cases}\frac{\gamma_{i}}{\left(1-\gamma_{1} \sigma_{1}\right) \tau}, & \text { if } 1-\gamma_{1} \sigma_{1}>0, \\ \gamma_{i} c_{1}^{-\sigma_{1}}, & \text { if } 1-\gamma_{1} \sigma_{1}=0 .\end{cases}
$$

At

$$
\tau \rightarrow \infty, \psi_{i} \rightarrow 0
$$

And

$$
\left\{\begin{array}{l}
\frac{\partial w_{1}}{\partial \tau}=\frac{\partial}{\partial x}\left(D_{1} w_{1}^{\sigma_{1}} \frac{\partial w_{1}}{\partial x}\right), \\
\left.\frac{\partial w_{2}}{\partial \tau}=\frac{\partial}{\partial x}\left(D_{2} w_{2}^{\sigma_{2}} \frac{\partial w_{2}}{\partial x}\right)\right) .
\end{array}\right.
$$

Let $\gamma_{1} \sigma_{1}>0, \gamma_{1} \sigma_{1}=\gamma_{2} \sigma_{2}, c_{i}>0$. In this case, assuming

$$
w_{i}(\tau(t), x)=y_{i}(\xi), \quad \xi=|x| / \tau_{1}^{1 / 2}, \quad i=1,2
$$

And considering that the equation for $w_{i}(\tau, x)$ without younger members is always self-similar, we obtain the system

$$
\left\{\begin{array}{l}
\xi^{-N} \frac{d}{d \xi}\left(\xi^{N-1} y_{1}^{\sigma_{1}} \frac{d y_{1}}{d \xi}\right)+\frac{\xi}{2 \theta_{1}} \frac{d y_{1}}{d \xi}-\mu_{1}\left(y_{1}-y_{1} y_{2}^{\beta_{1}}\right)=0 \\
\xi^{1-N} \frac{d}{d \xi}\left(\xi^{N-1} y_{2}^{\sigma_{2}} \frac{d y_{2}}{d \xi}\right)+\frac{\xi}{2 \theta_{2}} \frac{d y_{2}}{d \xi}+\mu_{2}\left(y_{2}-y_{2} y_{1}^{\beta_{2}}\right)=0
\end{array}\right.
$$

Where,

$$
\begin{array}{ll}
\mu_{i} & =\frac{1}{\theta_{i} \sigma_{i}}, \\
\theta_{i} & = \begin{cases}1, & \text { at } i=1, \\
c_{1}^{-\sigma_{1}} c_{2}^{\sigma_{2}}, & \text { at } i=2 .\end{cases}
\end{array}
$$

The study of qualitative properties of the system (1)-(2) enabled us to perform numerical experiment depending on the values included in the system of numeric parameters. For this purpose, as the initial approximation were used constructed asymptotic solutions. At the numerical solving of the task for the linearization of the system (1) - (2) were used linearization by methods of Newton and Picard. To solve the task of biological populations proposed the method of nonlinear splitting.

\section{NUMERICAL EXPERIMENT.}

To the numerical solving of the task (3)-(4) we construct a uniform grid

$$
\omega_{h}=\left\{x_{i}=i h, \quad h>0, i=0,1, \ldots, n, \quad h n=l\right\},
$$

And temporary grid

$$
\omega_{h_{1}}=\left\{t_{j}=j h_{1}, \quad h_{1}>0, \quad j=0,1, \ldots, n, \quad \tau m=T\right\}
$$

The main problem in nonlinear tasks is the suitable choice of the initial approximation and the method of linearization of the equation (3).

Replace task (3)-(4) with implicit difference scheme and receive differential task with the error $O\left(h^{2}+h_{1}\right)$.

Created on input language MathCad program allows visually trace the evolution process for different values of the parameters and data.

Numerical calculations show that in the case of arbitrary coefficients $\sigma, \beta$ qualitative properties of the solutions do 
not change. Below listed results of numerical experiments for different values of parameters.

\begin{tabular}{|c|c|c|}
\hline Parameter values & $\begin{array}{l}\text { Results of numerical experiment at } \\
\text { the initial moment of time }\end{array}$ & $\begin{array}{l}\text { Results of numerical experiment in } \\
\text { the final moment of time }\end{array}$ \\
\hline $\begin{array}{l}\sigma=1.1, p=2, m=2 \\
\beta_{1}=2, \quad k_{1}=5 \\
\beta_{2}=5, \quad k_{2}=2 \\
\text { eps }=10^{-3}\end{array}$ & '- A & \\
\hline & timel(FRAME + 1), time2(FRAME + 1) & time 1(FRAME + 100), time2(FRAME + 100) \\
\hline $\begin{array}{l}\sigma=1.3, p=2, m=2 \\
\beta_{1}=3, k_{1}=5 \\
\beta_{2}=7, \quad k_{2}=3 \\
\text { eps }=10^{-3}\end{array}$ & (1) & \\
\hline & timel (FRAME + 1), time2(FRAME + 1) & timel (FRAME + 100), time2(FRAME + 100) \\
\hline
\end{tabular}




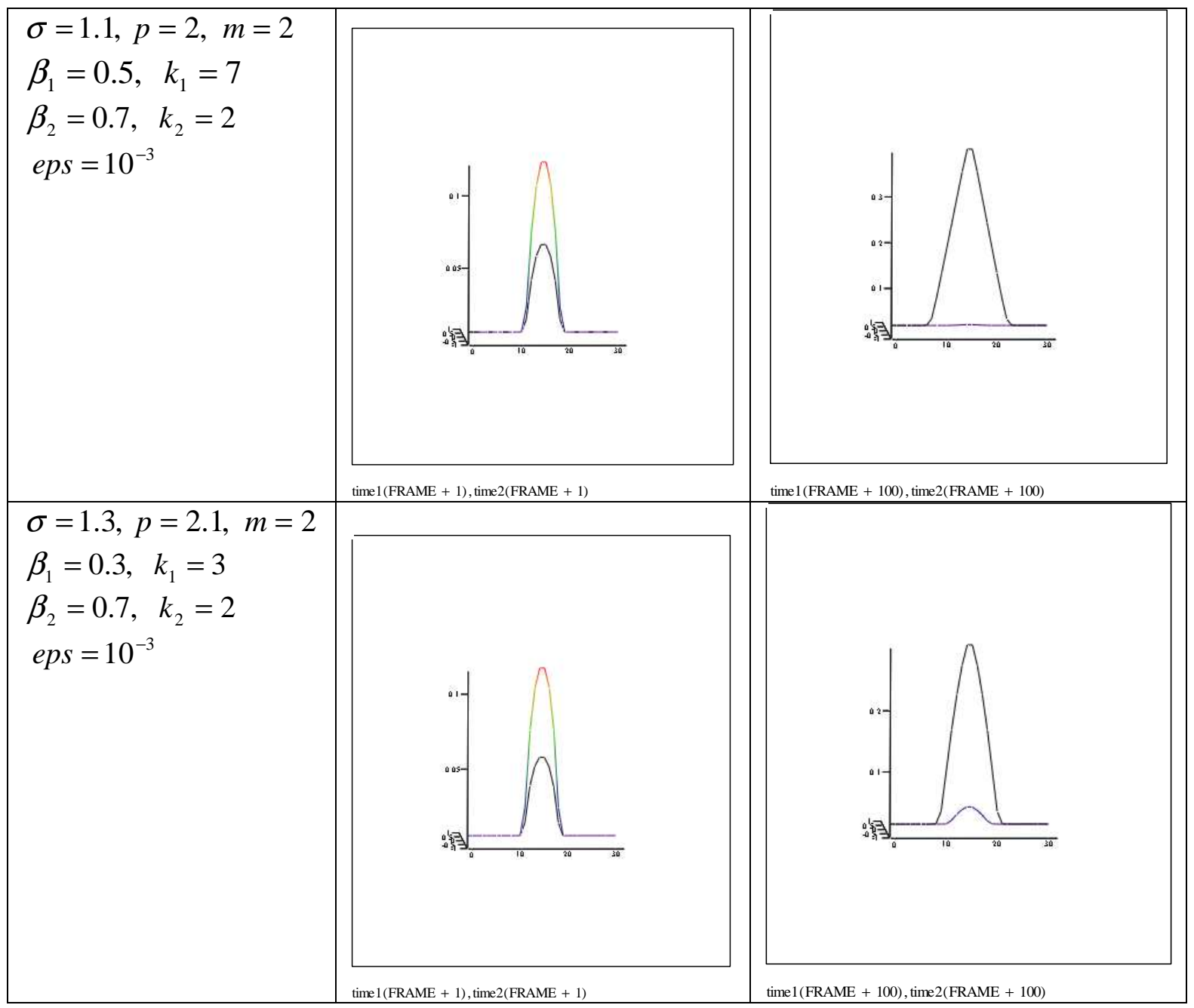

Fig 1. Results of numerical experiments

\section{CONCLUSIONS}

Results of numerical experiments showed the effectiveness of the proposed approach. Asymptotes of different solutions of the system of type (1) -(2) allowed to modeling processes of mutual reaction-diffusion in the form of visualization with animation.

In conclusion, we emphasize the importance of a joint study of migration and demographic processes. For the analysis of the population dynamics of interacting populations is important to collaborative learning processes of fertility, mortality, and trophic interactions of various migrations. Introduction of nonlinearity in migration flows - the first step towards an adequate description of the spatial and temporal population dynamics.

\section{REFERENCES}

[1]. Мари Дж. Нелинейные диффузионные уравнения в биологии. М., Мир,1983, 397 р.

[2]. M. Aripov (1997). «Approximate Self-similar Approach tu Solve Quasilinear Parabolic Equation» Experimentation, Modeling and Computation in Flow Turbulence and Combustion vol. 2. p. 19- 26.

[3]. Aripov M., Sadullaeva Sh.A. To solutions of one nondivergent type parabolic equation with double nonlinearity, Proceedings, ISAAC09-02, pp 592-596.

[4]. Арипов М. Метод эталонных уравнений для решения нелинейных краевых задач Ташкент, Фан, 1988, 137 р.

[5]. В. Вольтерра. Математическая теория борьбы за существование -М.: Наука, 1976, 288 р.

[6]. Гаузе Г.Ф. О процессах уничтожения одного вида другим в популяциях инфузорий // Зоологический журнал, 1934, т.13, №1. 
[7]. В. А. Галактионов, С. П. Курдюмов, А. А. Самарский Дифференциальныеуравнения 1983 т. 19 №12 с. 2123-2140 [8]. В. А. Галактионов, С. П. Курдюмов, А. А. Самарский Дифференциальные уравнения 1985 т. 21 №10 с. 15441559

[9]. Белотелов Н.В., Лобанов А.И.Популяционные модели с нелинейной диффузией. // Математическое моделирование. -М.; 1997, №12, стр. 43-56.

[10]. Explosion et existence global pour un system faiblement couple degation derection diffusion A 11 C-r. Acad. Sci. Ser. 1. 1992, 314. 10. Ct. 735-739

[11]. Рапопорт И. М. О некоторых асимптотических методах дифференциальных уравнений. Киев изд. АН УССР, 1954, - 287 p. 